05.1;07.2;08.1;13.1

\title{
Особенности роста гетероструктур нитрида галлия на подложках кремния: управляемая пластическая деформация
}

\author{
() И.С. Езубченко, М.Я. Черных, П.А. Перминов, Ю.В. Грищенко, И.Н. Трунькин, \\ И.А. Черных, М.Л. Занавескин
}

Национальный исследовательский центр „Курчатовский институт“, Москва, Россия

E-mail: ezivan9@gmail.com

Поступило в Редакцию 12 марта 2021 г.

В окончательной редакции 6 апреля 2021 г.

Принято к публикации 20 апреля 2021 г.

\begin{abstract}
Методом газофазной эпитаксии из металлоорганических соединений выращены нитрид-галлиевые гетероструктуры на подложках кремния. Обнаружены пластические деформации подложки при температурах 930-975 $\mathrm{C}$, возникающие в процессе роста при эффективном накоплении сжимающих напряжений в пленке. Предложен способ осуществления управляемой пластической деформации кремния за счет проведения высокотемпературного отжига, совмещенного с ростом in situ слоя $\mathrm{SiN}_{x}$, после роста гетероструктуры. Данный подход позволит упростить подбор архитектуры нитрид-галлиевых гетероструктур для различных технологических задач.
\end{abstract}

Ключевые слова: нитридная гетероструктура, металлоорганическая газофазная эпитаксия, нитрид галлия, кремний, пластическая деформация.

DOI: 10.21883/PJTF.2021.14.51183.18766

Гетероструктуры на основе нитрида галлия являются базой для современных мощных СВЧ-устройств [1,2]. Развитие технологий создания структур $\mathrm{GaN}$ на $\mathrm{Si}$ и транзисторов на их основе является перспективным с точки зрения удешевления производства ввиду доступности пластин кремния большого диаметра, простоты его механической обработки и возможности адаптации нитридных технологий на кремнии к современному кремниевому производству [3].

Однако значительное различие параметров решеток и коэффициентов теплового расширения (КТР) $\mathrm{GaN}$ и $\mathrm{Si}$ делает задачу синтеза ненапряженных гетероструктур высокого кристаллического качества на кремнии существенно более сложной, чем в случае подложек сапфира или карбида кремния. Кроме того, архитектура гетероструктуры, состав, толщины, а также степень легирования ее слоев могут варьироваться в зависимости от назначения разрабатываемых устройств.

В настоящей работе предложен подход, использование которого позволит избежать растрескивания структуры в процессе остывания, а также упростить подбор архитектуры слоев для создания гетероструктур нитрида галлия приборного качества за счет осуществления управляемой пластической деформации кремния в процессе роста.

Кремний испытывает переход от хрупкости к пластичности при температурах, составляющих более $60 \%$ от его абсолютной температуры плавления $\left(1412^{\circ} \mathrm{C}\right)$ [4]. Таким образом, при ростовых температурах, используемых для эпитаксии гетероструктур нитрида галлия, подложка кремния способна пластически деформироваться. Однако условия осуществления и контроль ее пластиче- ских деформаций, а также возможность использования данного эффекта при создании устройств на основе $\mathrm{GaN}$ мало изучены.

Были выращены четыре образца нитридных гетероструктур $(A, B, C, D)$ методом газофазной эпитаксии из металлоорганических соединений на установке AIXTRON 2600 G3. В качестве подложек для роста были использованы высокоомные пластины кремния $\mathrm{Si}(111)$ диаметром $2^{\prime \prime}$ и толщиной $500 \mu \mathrm{m}$, полученные методом зонной плавки. Детали роста гетероструктур приведены в [5]. Буферный слой AlN формировался в две стадии и состоял из низкотемпературного $(30 \mathrm{~nm}$, $\left.795^{\circ} \mathrm{C}\right)$ и высокотемпературного $\left(70 \mathrm{~nm}, 925^{\circ} \mathrm{C}\right)$ слоев. Затем были выращены три слоя $\mathrm{AlGaN}$ с толщинами 270,350 и $350 \mathrm{~nm}$ и процентным содержанием Al 80, 50 и $30 \%$ соответственно, канальный слой $\mathrm{GaN}$ толщиной $1.35 \mu \mathrm{m}$ и барьерный слой $\mathrm{AlN}$ толщиной $4.5 \mathrm{~nm}$. Для накопления дополнительных сжимающих напряжений образцы $A, B$ и $C$ формировались с включением низкотемпературной вставки AlN $(10 \mathrm{~nm}$ для образца $A$ и $15 \mathrm{~nm}$ для образцов $B$ и $\left.C, 800^{\circ} \mathrm{C}\right)$ в слой нитрида галлия. Для образца $B$ после роста был проведен отжиг. Кроме того, на образцах $C$ и $D$ был сформирован слой in situ пассивации $\mathrm{SiN}_{x}$ толщиной $7 \mathrm{~nm}$ с использованием моносилана в качестве источника кремния. Отжиг (для образца $B$ ) и осаждение слоя пассивации (для образцов $C$ и $D)$ осуществлялись в идентичных условиях в течение часа непосредственно после роста барьерного слоя $\left(975^{\circ} \mathrm{C}, 5 \mathrm{kPa}\right)$. В процессе роста обеспечивался контактный нагрев подложки подложкодержателем. In situ контроль температуры подложки и толщин слоев проводился при помощи системы Laytec Epi TT на длине 
волны $\lambda=880 \mathrm{~nm}$. Исследования образцов методами атомно-силовой $(\mathrm{ACM})$ и просвечивающей растровой электронной микроскопии (ПРЭМ) проводились с использованием микроскопов Ntegra Prima (NT-MDT) и Titan 80-300 (FEI).

Конфигурация буферных слоев нитридной гетероструктуры была подобрана таким образом, чтобы скомпенсировать растягивающие напряжения, возникающие в пленке при охлаждении из-за различий КТР кремния и нитридов. В процессе эпитаксии происходит накопление сжимающих напряжений, что приводит к выпуклой форме образца при температурах роста. По мере накопления напряжений изгиб и соответственно расстояние между центром образца и подложкодержателем увеличивается, что приводит к понижению температуры в центре подложки.

На рис. 1, $a$ приведена зависимость температуры центра образца $A$ от времени в процессе роста канального слоя $\mathrm{GaN}$ после низкотемпературной вставки. На температурной зависимости есть точка излома, в которой происходит изменение скорости понижения температуры. Это указывает на включение дополнительного механизма, оказывающего влияние на изгиб образца. В работе [6] было показано, что в качестве такого механизма могут выступать пластические деформации кремниевой подложки.

На рис. 1, $b$ приведено ПРЭМ-изображение гетерограницы $\mathrm{AlN}-\mathrm{Si}$ образца $A$. Для образца характерно наличие локальных дефектов в кремнии, вызванных смещением кристаллических плоскостей. После остывания образец обладал выпуклой формой с кривизной более $450 \mathrm{~km}^{-1}$, а также определенной степенью асферичности, связанной с неоднородностью протекания процесса пластической деформации по образцу.

Таким образом, пластическая деформация кремния в процессе роста приводит к возникновению существенного изгиба, который не компенсируется разницей КТР и сохраняется после остывания [7], а также асферичности образца [8], что делает невозможным дальнейшее формирование устройств. Кроме того, дефекты, возникающие в кремнии, могут негативно сказаться на работе конечных приборов.

Для остальных образцов была выбрана архитектура, обеспечивающая меньшее накопление сжимающих напряжений, чем на образце $A$, чтобы избежать пластических деформаций непосредственно в процессе роста $\mathrm{GaN}$. Для этого были изменены параметры роста низкотемпературной вставки [9]. На рис. 2, а приведены зависимости температур центров образцов от времени после роста канального слоя, т.е. в процессе формирования барьерного слоя и последующего отжига, который для образцов $C$ и $D$ был совмещен с ростом $\mathrm{SiN}_{x}$.

На образцах $B$ и $C$ наблюдалось понижение температуры центра спустя некоторое время после начала отжига, что указывает на протекание процесса пластических деформаций. Однако в отличие от образца $A$ они проходили в отсутствие значительного дополнительного
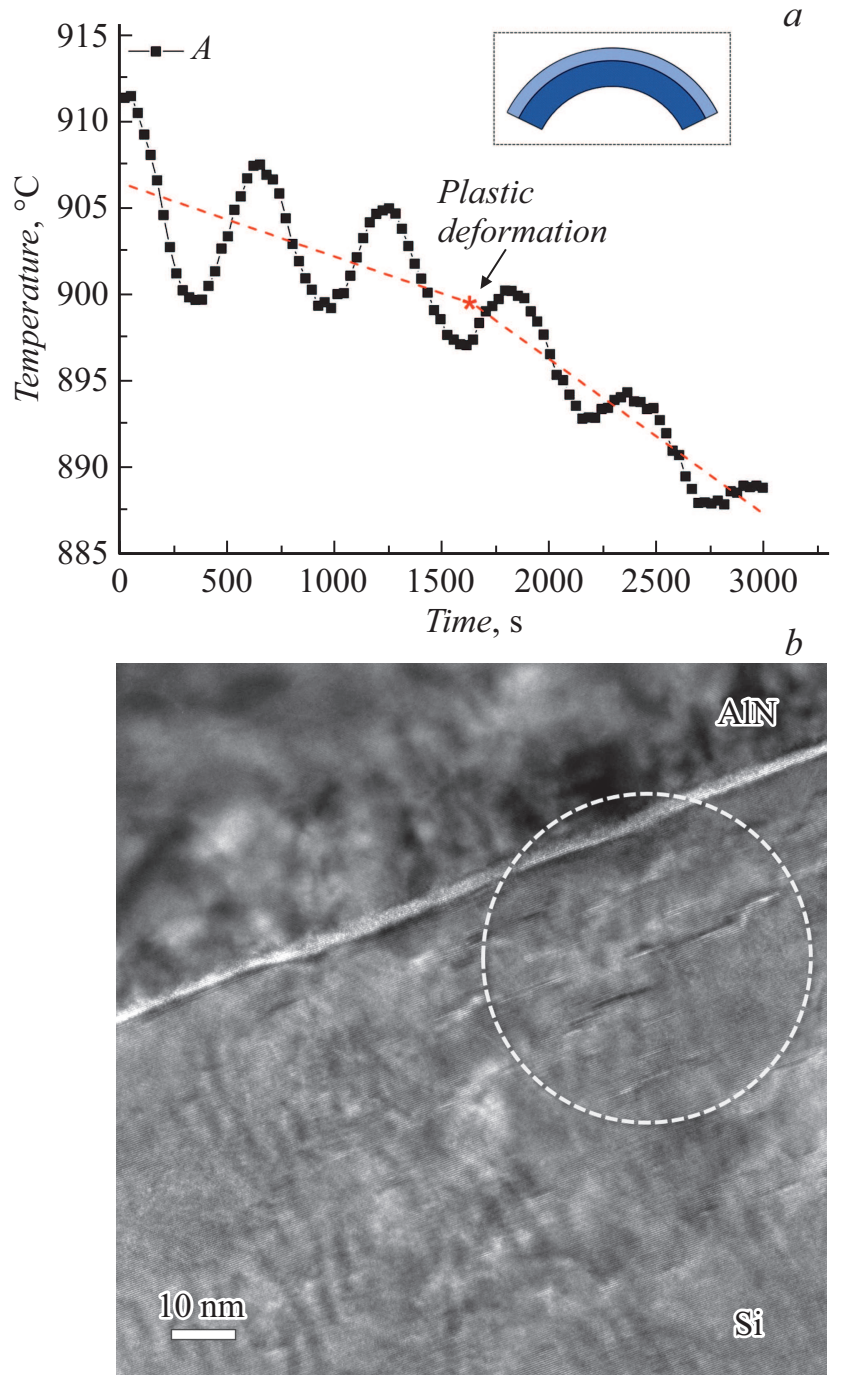

Рис. 1. $a-$ зависимость температуры центра образца $A$ от времени. На вставке приведено схематическое изображение выгнутой подложки в процессе роста. $b-$ ПРЭМ-изображение гетерограницы $\mathrm{AlN}-\mathrm{Si}$ образца $A$. Выделена дефектная область в кремнии.

накопления сжимающих напряжений, которое происходило при росте $\mathrm{GaN}$ после вставки, что выражается в меньшей скорости изменения температуры центра (в несколько раз). Следовательно, процесс пластической деформации кремния в данном случае протекает более плавно. После остывания образцы $B$ и $C$ имели выпуклую форму с кривизной 50 и $200 \mathrm{~km}^{-1}$ соответственно.

На образце $D$, сформированном без вставки в канальном слое, понижения температуры не наблюдалось. Данная архитектура не обеспечила эффективное накопление компенсирующих сжимающих напряжений в процессе роста структуры, после остывания пленка потрескалась, и образец $D$ имел вогнутую форму с кривизной $70 \mathrm{~km}^{-1}$. Таким образом, процесс деформации не является результатом только лишь термических преобразований кристаллической решетки кремния, а происходит после 

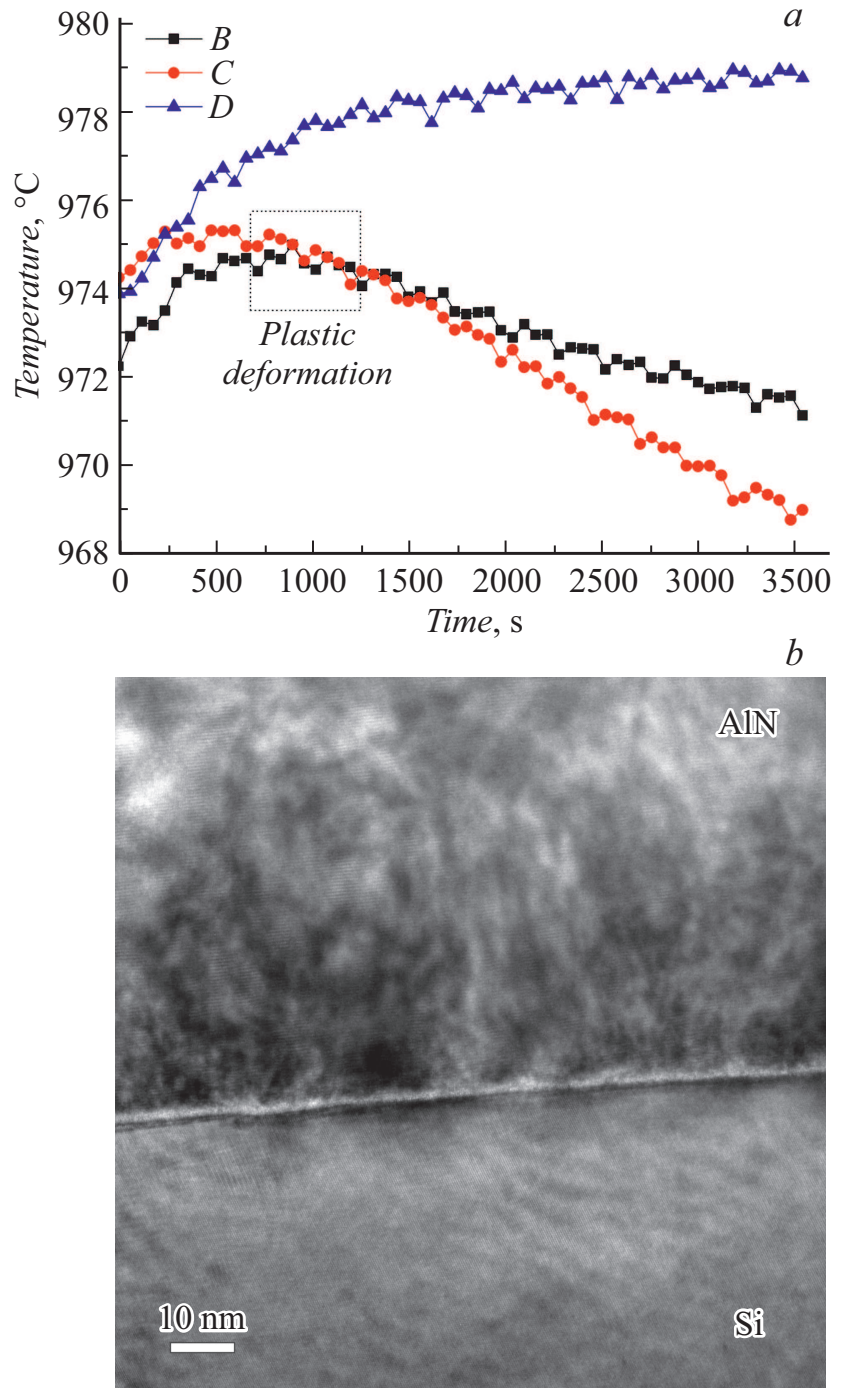

Рис. 2. $a-$ зависимости температур центров образцов $B, C$, $D$ от времени. $b-$ ПРЭМ-изображение гетерограницы $\mathrm{AlN}-\mathrm{Si}$ образца $C$.

накопления определенных для данной ростовой температуры сжимающих напряжений в пленке.

ПРЭМ-исследование гетерограницы $\mathrm{AlN}-\mathrm{Si}$ для образца $C$ показало отсутствие локальных дефектов в кремнии в центре образца (рис. 2,b). Для образцов не наблюдалось асферичности. По всей видимости, при пластической деформации дефекты в кремнии возникают в первую очередь на краях и по мере протекания деформации формируются все ближе к центру образца. Контролируя процесс, можно обеспечить незначительные пластические деформации подложки и при этом синтезировать структуру с небольшой кривизной и отсутствием дефектов в центральной части пластины.

АСМ-исследование поверхности сформированных пленок показало, что для образца $B$ характерно наличие областей травления, сформированный же на образце $C$ слой $\mathrm{SiN}_{x}$ помогает защитить структуру (рис. 3).
Таким образом, с использованием подхода осаждения in situ слоя $\mathrm{SiN}_{x}$ удается не только сформировать пассивирующий для структуры слой, защищающий от деградации канала двумерного электронного газа после извлечения образца на атмосферу, а также при проведении последующих технологических операции по созданию транзисторов, но и за счет подбора условий осаждения обеспечить контролируемое осуществление пластических деформаций в подложке при высоких температурах, не допуская растравливания пленки в агрессивной среде водорода.

В работе были выращены нитрид-галлиевые гетероструктуры на подложках кремния методом газофазной эпитаксии из металлоорганических соединений. Обнаружено, что при высоких температурах в случае эффективного накопления в нитридной пленке сжимающих напряжений возникают пластические деформации подложки. Одним из способов осуществления управляемой

a

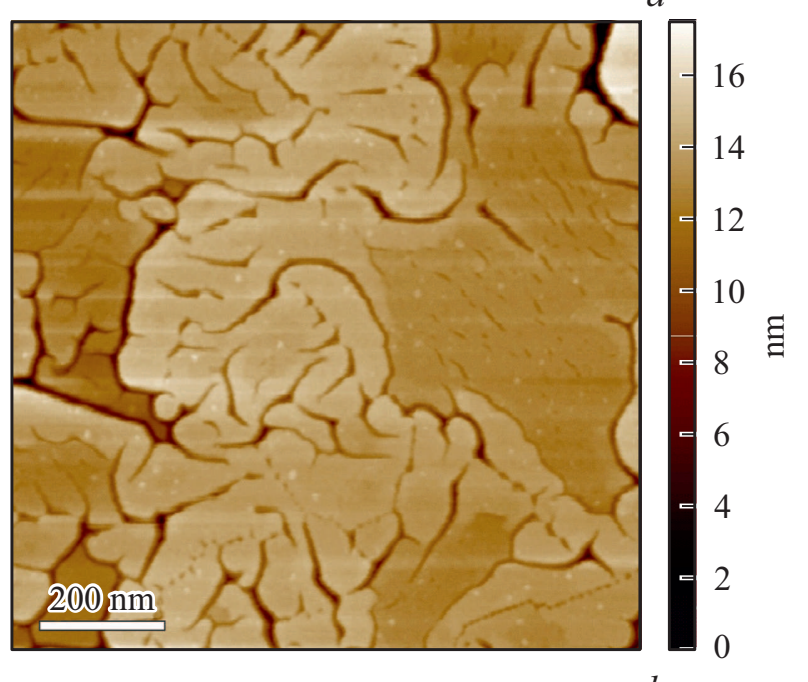

b

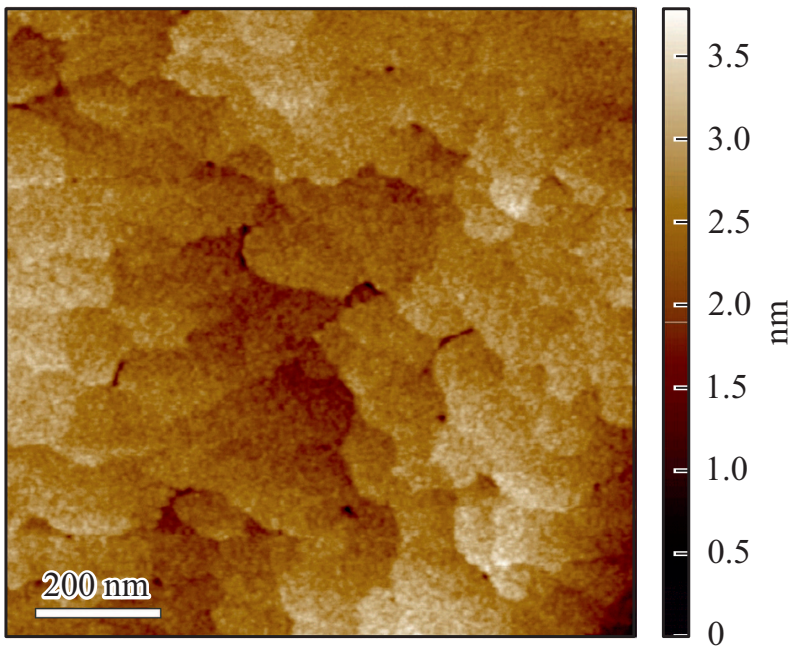

Рис. 3. АСМ-изображения поверхности образцов. $a-$ образец $B$ без пассивирующего слоя, $b-$ образец $C$ со слоем in situ пассивации $\mathrm{SiN}_{x}$. 
пластической деформации кремния является проведение высокотемпературного отжига после роста гетероструктуры, совмещенного с ростом пассивирующего in situ слоя $\mathrm{SiN}_{x}$. Было показано, что при плавном протекании процесса локальные дефекты в центре пластины отсутствуют. Контроль за деформациями может быть обеспечен путем изменения температуры и времени формирования пассивирующего слоя. Использование данного эффекта позволит формировать гетероструктуры с близкой к нулю кривизной подложки без дефектов в рабочей зоне пластины и значительно упростит подбор архитектуры структуры для разных технологических задач.

\section{Финансирование работы}

Работа выполнена при финансовой поддержке Национального исследовательского центра „Курчатовский институт“" (приказ № 1055 от 02.07.2020 г.).

\section{Конфликт интересов}

Авторы заявляют, что у них нет конфликта интересов.

\section{Список литературы}

[1] T. Ueda, Jpn. J. Appl. Phys., 58, SC0804 (2019). DOI: $10.7567 / 1347-4065 / a b 12 c 9$

[2] P. Fay, D. Jena, P. Maki, High-frequency GaN electronic devices (Springer, Cham, 2020), p. 1-40.

[3] K.J. Chen, O. Häberlen, A. Lidow, C.L. Tsai, T. Ueda, Y. Uemoto, Y. Wu, IEEE Trans. Electron Dev., 64 (3), 779 (2017). DOI: 10.1109/TED.2017.2657579

[4] Y. Cao, O. Laboutin, C.-F. Lo, K. O'Connor, D. Hill, W. Johnson, in 2014 CS MANTECH digest (Denver, 2014), p. 261. https://csmantech.org/ Digests/2014/papers/073.pdf

[5] И.С. Езубченко, М.Я. Черных, А.А. Андреев, Ю.В. Грищенко, И.А. Черных, М.Л. Занавескин, Рос. нанотехнологии, 14 (7-8), 77 (2019).

DOI: $10.21517 / 1992-7223-2019-7-8-77-80$

[Пер. версия: 10.1134/S1995078019040050].

[6] L. Zhang, K.H. Lee, I.M. Riko, C.-C. Huang, A. Kadir, K.E. Lee, S.J. Chua, E.A. Fitzgerald, Semicond. Sci. Technol., 32 (6), 065001 (2007). DOI: 10.1088/1361-6641/aa681c

[7] P.-J. Lin, C.-H. Tien, T.-Y. Wang, C.-L. Chen, S.-L. Ou, B.-C. Chung, D.-S. Wuu, Crystals, 7 (5), 134 (2017). DOI: $10.3390 /$ cryst7050134

[8] A. Dadgar, S. Fritze, O. Schulz, J. Hennig, J. Blasing, H. Witte, A. Diez, U. Heinle, M. Kunze, I. Daumiller, K. Haberlan, A. Krost, J. Cryst. Growth, 370 (1), 278 (2013). DOI: $10.1016 /$ j.jcrysgro.2012.07.017

[9] A. Krost, A. Dadgar, G. Strassburger, R. Clos, Phys. Status Solidi A, 200 (1), 26 (2003). DOI: 10.1002/pssa.200303428 